\title{
Stress field evolution in the North West Himalayan syntaxis (Northern Pakistan)
}

\author{
A Pêcher ${ }^{1 *}$, S Guillot ${ }^{1}$, F Jouanne'2, G Mahéo ${ }^{3}$, JL Mugnier ${ }^{2}$, Y Rolland ${ }^{4}$, P Van der Beek ${ }^{1}$ and J Van Melle \\ 1 LGCA, UMR 5025, CNRS - Université Joseph Fourier, FRANCE \\ 2 LGCA, UMR 5025, CNRS - Université de Chambéry, FRANCE \\ 3 UMR5570, CNRS - Université Claude Bernard - ENS Lyon, FRANCE \\ ${ }^{4}$ Geosciences Azur, UMR 6526, CNRS - Université de Nice, FRANCE \\ *For correspondance, email: arnaud.pecher@uif-grenoble.fr
}

In North-West Himalaya (Western Syntaxis) coexist both early stabilized parts of the belt, stable since Miocene (Kohistan, Deosai, for instance) and zone of active relief where deep parts of the crust have been very recently exhumed (late Miocene and Plio-Quaternary exhumation, in Karakorum and Nanga Parbat). This contrasted pattern was acquired in a context characterized by a strong partition of the deformation: from place to place, the structures can indicate shortening parallel to the bulk Himalayan convergence (Karakorum for instance), or at the opposite parallel to the belt strike (Nanga Parbat spur, Becham syntaxis, Murree syntaxis). A systematic study of the brittle deformation in those areas has been conducted (inversion of fault striations on fault planes to estimate the palaeostress state), in order to depict variations in time and space of the palaeostress field in this part of Himalaya.

At a regional scale, two main domains can be separated (Pecher et al., submitted), limited by the Raikhot fault, a reverse fault still active, bounding to the West the Nanga Parbat North-South pop-up anticlinal. West of this fault, in Kohistan and Karakorum, the predominant stress field is characterized by vertical $\sigma 2$ and close to N-S $\sigma 1$ (deformation field mainly

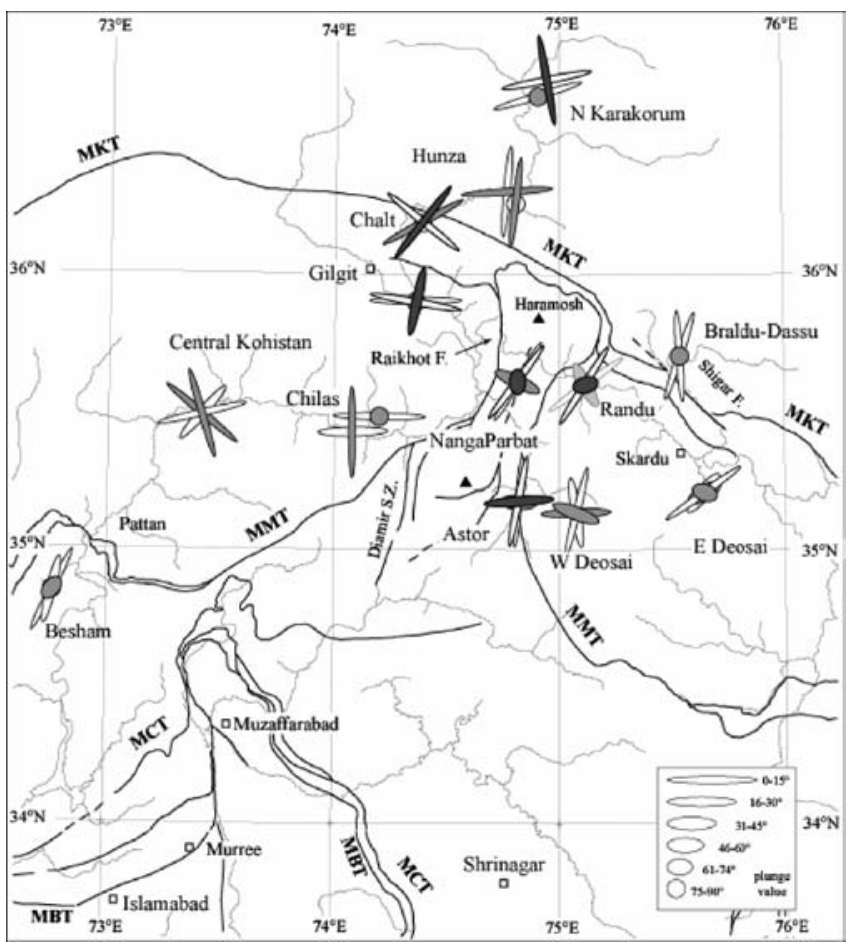

controlled by strike slip faults). It predates the Plio-Quaternary exhumation of the Nanga Parbat, and would correspond to the regional stress field inducted by the India-Asia convergence. East of the Raikhot fault, compression is parallel to the belt. It acts for the N-S structure of the Nanga Parbat, probably initiated around $5 \mathrm{Ma}$ ago. Since $2 \mathrm{Ma}$, the stress field seems mainly extensive, the predominant extension being either perpendicular to the belt (NNE-SSW), or more often parallel to the belt strike (NW-SE).

Thus in North-West Himalaya, multidirectional extension is superimposed to shortening either parallel or perpendicular to the belt. Such a pattern implies a great instability of the stress field both in space (at a few tens km scale) and time (at one Ma scale or less). It could be a characteristic feature of crustal-scale strain partitioning in a oblate convergence context.

\section{References}

Pêcher A, L Seeber, S Guillot, F Jouanne, A Kausar, M Latif, A.

Madji, G Mahéo, JL Mugnier, Y Rolland, P van der Beek and J Van Melle. Stress field evolution in the Northwest Himalayan syntaxis, Northern Pakistan (submitted)
FIGURE 1. Regional stress orientations in Northern Pakistan. Regional tensors calculated by merging faults measured in 4 to 11 individual outcrop-scale sites. Each stress axis is indicated by an ellipse: the great axis of the ellipse gives the azimuth of the principal stress axis, the shape of the ellipse its plunge (classes of $15^{\circ}$ ). For each area, only the two best tensors are shown. T1: $\sigma 1$ in black, $\sigma 3$ thick plain symbol; T2: $\sigma 1$ in grey, $\sigma 3$ light plain symbol (in Pecher et al. submitted) 